\title{
Variations in Cochlear Size of Cochlear Implant Candidates
} \author{
Taufik Ashar ${ }^{4}$ () \\ ${ }^{1}$ Department of Otorhinolaryngology - Head and Neck Surgery, \\ Faculty of Medicine, Universitas Sumatera Utara, Medan, Sumatera \\ Utara, Indonesia \\ 2 Department of Otorhinolaryngology - Head and Neck Surgery, \\ Faculty of Medicine, and Health Sciences, Universitas Islam Negeri \\ Syarif Hidayatullah Jakarta, Jakarta, Indonesia \\ ${ }^{3}$ Department of Radiology, Faculty of Medicine, Universitas Sumatera \\ Utara, Medan, Sumatera Utara, Indonesia \\ ${ }^{4}$ Department of Environmental Health, Faculty of Public Health, \\ Universitas Sumatera Utara, Medan, Sumatera Utara, Indonesia \\ Int Arch Otorhinolaryngol 2019;23:184-190.
}

Devira Zahara ${ }^{1}$ Rima Diana Dewi ${ }^{1} \quad$ Askaroellah Aboet $^{1}$ Fikri Mirza Putranto ${ }^{2}$ Netty Delvrita Lubis $^{3}$

\begin{abstract}
Address for correspondence Devira Zahara, MD, ENT Specialist, PhD, Department of Otorhinolaryngology - Head and Neck Surgery, Faculty of Medicine, Universitas Sumatera Utara, Jalan Dr. T. Mansur No.5, Medan, 20155, Sumatera Utara, Indonesia (e-mail: d3_za@yahoo.com).
\end{abstract}

\begin{abstract}
Introduction The cochlear anatomy varies in each individual, and that has an impact on decisions regarding the insertion of electrodes. The measurement of the cochlear size is the routine examination required to choose the proper cochlear implant $(\mathrm{Cl})$ electrodes.

Objective To acquire normative data on the size of the cochlea (length, width, height, scala timpani [ST] height, cochlear duct length [CDL]) of $\mathrm{Cl}$ candidates in Medan, Indonesia.

Methods This descriptive study was conducted based on high-resolution computed tomography (HRCT) temporal bone data and on HRCT temporal data manipulated to reconstruct three-dimensional (3D) multiplanar images with OsiriX MD DICOM Viewer version 9.5.1 (Pixmeo SARL, Bernex, Geneva, Switzerland) viewer of 18 patients (36 ears) who were $\mathrm{Cl}$ candidates in Medan, Indonesia, in order to determine cochlear length (A), cochlear width, cochlear height, ST height and CDL, calculated through a simple mathematical function.

Results The average cochlear length (A) was $8.75 \mathrm{~mm}$ (standard deviation [SD] $=0.31 \mathrm{~mm})$; the average cochlear width was $6.53 \mathrm{~mm}(\mathrm{SD}=0.35 \mathrm{~mm})$; the average cochlear height was $3.26 \mathrm{~mm}(\mathrm{SD}=0.24 \mathrm{~mm})$ and the average ST height at the basal cochlea was $1.00 \mathrm{~mm}(\mathrm{SD}=0.1 \mathrm{~mm})$; and $0.71 \mathrm{~mm}(\mathrm{SD}=0.1 \mathrm{~mm})$ at the half turn of

\section{Keywords}

- cochlea

- cochlear implant

- computed tomography

- temporal bone cochlea. The average total $C D L$ was $32.45 \mathrm{~mm}(S D=1.31 \mathrm{~mm}$; range: $30.01-34.83$ $\mathrm{mm})$.

Conclusion The cochlear size varies in each individual; therefore, the temporal bone measurement of $\mathrm{Cl}$ candidates using HRCT is essential: for the selection of suitable implant electrodes; to minimize cochlear damages at the insertion of the electrode arrays; and to maximize the hearing improvements.
\end{abstract}

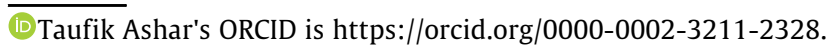

received

February 11, 2018

accepted

May 6, 2018

published online

October 24, 2018
DOI https://doi.org/

10.1055/s-0038-1661360. ISSN $1809-9777$.
Copyright (e 2019 by Thieme Revinter

Publicações Ltda, Rio de Janeiro, Brazil
License terms

c) $(1) \$$ 


\section{Introduction}

Congenital sensorineural hearing loss is generally bilateral, and most of the cases present severe to profound hearing loss. ${ }^{1-3}$ Hearing rehabilitation with a cochlear implant $(\mathrm{CI})$ for electrical stimulation of the auditory nerve is a standard therapy for severe to profound congenital hearing loss that has received little or no benefit from hearing aids. ${ }^{1,2}$

Bony cochlear or vestibular malformations occur in $\sim 20$ to $25 \%$ of the patients with congenital hearing loss, which is indicated by a computed tomography (CT) of the temporal bone. Although the human cochlea reaches adult size before birth, it is known that the size of the cochlea varies between individuals, and that the cochlea differs significantly in shape, size and spiral characteristics. ${ }^{4-15}$ Currently, because of the variations among individuals, and in order to preserve the residual hearing, Cls tend to have dimensions designed for each individual cochlear size. Detailed quantified information about the variation of each individual cochlea is required to enable the design of the appropriate $\mathrm{Cl}$ electrode for each individual. ${ }^{6,8}$

A high-resolution computed tomography (HRCT) of the temporal bone is routinely performed before $\mathrm{CI}$ surgery. The HRCT can evaluate inner ear abnormalities, facilitate surgical planning, and define the features of the cochlear nerve, as well as identify the presence of malformations or ossifications that may limit the access to the scala timpani (ST). ${ }^{16-18}$ Preoperative prediction of the design of the CI electrode may help reduce the risk of intraoperative cochlear trauma in patients who need to preserve acoustic hearing for electroacoustic stimulation, or in patients with anomalies or malformations. Indications for cochlear implantation have been expanded to include not only deafness, but also severe hearing impairment with unsatisfactory speech perception through the use of hearing aids. $^{18-20}$

Knowing about individual cochlear variations is essential for the greatest possible electrode insertion with a minimal risk of injury. The implant may stimulate the rest of the spiral ganglion located in the cochlear apex. In some cases, the depth of the insertion can also be adjusted for residual hearing, especially in patients with severe to profound hearing loss at high and low frequencies, whose hearing is preserved to be given electroacoustic stimulation. Therefore, the measurement of the length of the cochlea is important to predict the proper insertion depth for each individual, to select the appropriate electrode, and for the planning of surgical techniques prior to Cl surgery. ${ }^{18,19}$

The purpose of the present study is to establish normative data on the size of the cochlea (cochlear length, width, height, ST height, cochlear duct length [CDL]) from HRCT temporal bone data of $\mathrm{CI}$ candidates in Medan, Indonesia.

\section{Methods}

In the present study, we included the HRCT temporal bone data of 18 patients ( 36 ears) aged between 2 and 17 years old, consisting of 11 men and 7 women, who presented congenital sensorineural hearing loss and had been screened for cochlear anomaly or malformation as $\mathrm{Cl}$ candidates in Medan, Indonesia, between October 2012 and September 2017. We excluded HRCT temporal bone data that could not be evaluated after multiplanar reconstruction. The Health Research Ethical Committee granted approval for the study.

The temporal bone data obtained through HRCT was used to perform a three-dimensional (3D) multiplanar reconstruction with OsiriX MD DICOM Viewer version 9.5.1 (Pixmeo SARL, Bernex, Geneva, Switzerland) viewer to obtain cochlear length $(\mathrm{A})$, cochlear width, cochlear height, and ST height. A view of the basal turn of the cochlea was developed in a double oblique coronal reformatted image, as shown in -Fig. 1. In one view, the round window, the oval window, the basal turn of the cochlea, the vestibule and the anterior branches of the lateral and superior semicircular canals can be seen. The view was developed to provide the largest distance from the round window through the mid modiolar axis to the lateral wall, which was measured as cochlear length, and the perpendicular distance, which was measured as cochlear width. $8,11,21,22$

The cochlear height [ - Fig. 2] was obtained from an axial image reconstructed from a temporal HRCT and was defined as the length between the tip of the cochlea and the orthogonal projection passing through the middle of the canal to the cochlear base. ${ }^{8,23}$

The ST height was measured at two locations: at the base of the cochlea and at the half-turn of the cochlea, which provided the center height of the ST, as shown in - Fig. $\mathbf{3 .}^{24}$

The CDL is the length of the scala media measured from the middle of the round window to 1 turn of the cochlea $\left(360^{\circ}\right)$, using the formula $2.43 \mathrm{~A}-2.43$. The formulas used to measure additional turns were: 1.5 turns $\left(540^{\circ}\right): 3 \mathrm{~A}-3.02 ; 2$ turns $\left(720^{\circ}\right)$ : $3.65 \mathrm{~A}-3.63 ; 2.5$ turns, or helicotrema $\left(900^{\circ}\right)$ : $4.16 \mathrm{~A}-3.98 .^{25,26}$

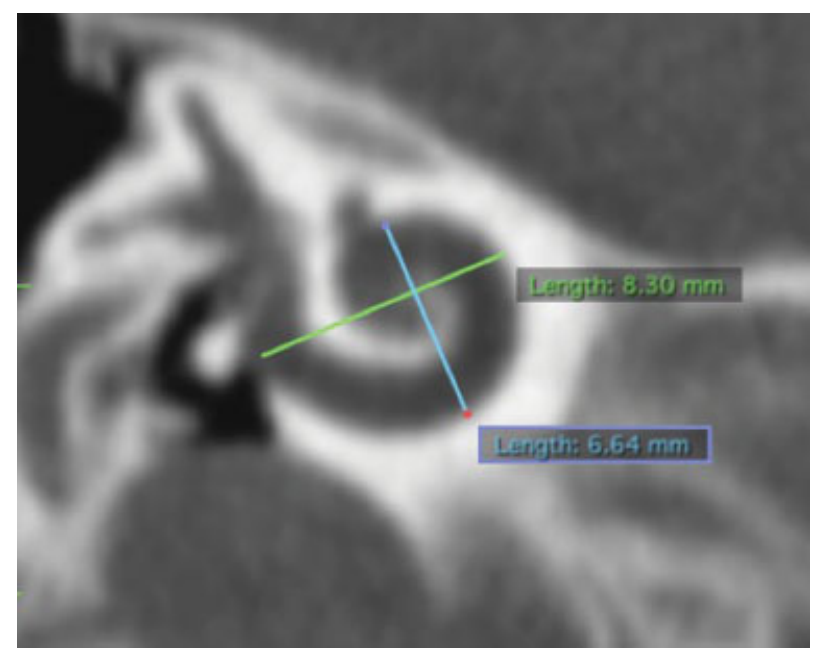

Fig. 1 A double-oblique coronal reformatted image. Distance A (cochlear length) of $8.30 \mathrm{~mm}$, and perpendicular distance (cochlear width) of $6.64 \mathrm{~mm}$. 


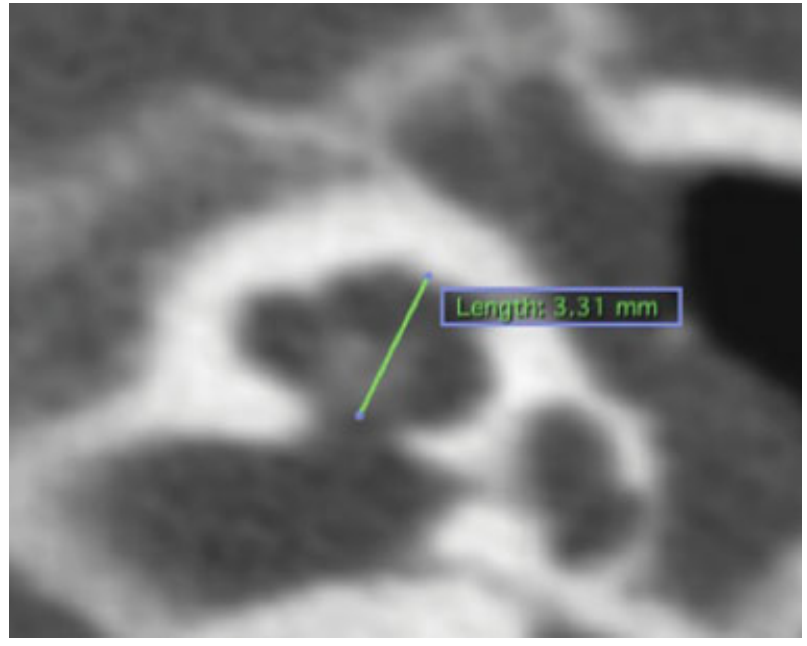

Fig. 2 Axial computed tomography of the left ear shows an example of the measurement of the cochlear height $(3.31 \mathrm{~mm})$.

\section{Results}

The mean value of the cochlear length (A) was $8.75 \mathrm{~mm}$ (standard deviation $[\mathrm{SD}]=0.31 \mathrm{~mm}$ ), the mean cochlear width was $6.53 \mathrm{~mm}(\mathrm{SD}=0.35 \mathrm{~mm})$, and the mean cochlear height was $3.26 \mathrm{~mm}(\mathrm{SD}=0.24 \mathrm{~mm})$, as shown in - Table 1 and in the box plots in - Fig. 4 (A). The mean ST height at the basal cochlea was $1.00 \mathrm{~mm}(\mathrm{SD}=0.1 \mathrm{~mm})$ and $0.71 \mathrm{~mm}$ $(\mathrm{SD}=0.1 \mathrm{~mm})$ at the half turn of the cochlea $\left(180^{\circ}\right)$, as shown in -Table 2 and in the box plots in -Fig. 4 (B). The mean length of the cochlear duct was: $18.85 \mathrm{~mm}(\mathrm{SD}=0.76$ $\mathrm{mm})$ at 1 turn of the cochlea $\left(360^{\circ}\right) ; 23.25 \mathrm{~mm}(\mathrm{SD}=0.94$ $\mathrm{mm})$ at 1.5 turns $\left(540^{\circ}\right) ; 28.33 \mathrm{~mm}(\mathrm{SD}=1.15 \mathrm{~mm})$ at 2 turns $\left(720^{\circ}\right)$; and $32.45 \mathrm{~mm}(\mathrm{SD}=1.31 \mathrm{~mm}$; range: $30.01-$ $34.83 \mathrm{~mm}$ ) at 2.5 turns $\left(900^{\circ}\right)$, as shown in - Table 3 and in the box plots in - Fig. 4 (C).

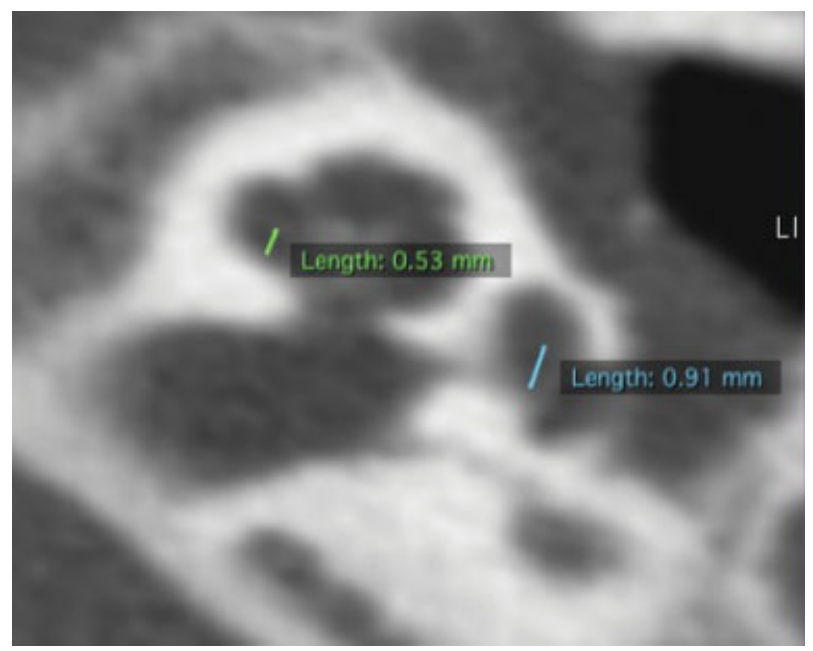

Fig. 3 Measurements of the height of the scala timpani on axial computed tomography image $(0.91 \mathrm{~mm}$ at the basal turn, and $0.53 \mathrm{~mm}$ at half-turn).
Table 1 Cochlear length, cochlear width and cochlear height

\begin{tabular}{|l|l|l|l|}
\hline & $\begin{array}{l}\text { Cochlear } \\
\text { length } \\
(\mathbf{m m})\end{array}$ & $\begin{array}{l}\text { Cochlear } \\
\text { width } \\
(\mathbf{m m})\end{array}$ & $\begin{array}{l}\text { Cochlear } \\
\text { height } \\
(\mathbf{m m})\end{array}$ \\
\hline Mean & 8.75 & 6.53 & 3.26 \\
\hline Median & 8.83 & 6.51 & 3.26 \\
\hline Standard deviation & 0.31 & 0.35 & 0.24 \\
\hline Minimum & 8.17 & 5.73 & 2.80 \\
\hline Maximum & 9.33 & 7.50 & 3.72 \\
\hline
\end{tabular}

\section{Discussion}

Important advances have been made in the insertion of electrodes into the cochlea during cochlear implantation, and they are especially focused on minimizing trauma during insertion and preserving the residual hearing. This result can be achieved with appropriate cochlear electrodes and less traumatic surgical techniques. ${ }^{7}$

There are extensive individual variations in cochlear size, which may influence its final position relatively to the cochlea place or the frequency map and final pitch discrimination. ${ }^{27}$ These variations have implications for the cochlear electrode insertion as well as for the design of the electrode array. $6,7,19$ There are various methods to measure the size of the cochlea. Advances in imaging technology with HRCT and 3D reconstructions can now reliably detect and quantify variations in the human cochlear anatomy. 8,11,17,28,29

Cochlear length measurements are important to estimate the depth of individual electrode insertion and to an appropriate electrode selection, as well as for the planning of surgical techniques prior to the $\mathrm{CI}$ surgery. A 3D multiplanar reconstruction analysis of the HRCT data enables a linear reconstruction of length measurements. In some cases, this will be helpful to choose the optimal electrode length before the CI surgery, to minimize intracochlear trauma, and to enable a proper electrode fitting. For electroacoustic stimulation (EAS) surgery, an appropriate prediction of the length of the electrode should be obtained in order to avoid trauma of the apical structures and to obtain good hearing performance. $^{18}$

Escude et al $^{11}$ developed a method for quantitative determination of the size of the cochlea using reconstructed images from routine HRCTs of the temporal bone. The full basal turn of the cochlea was visualized, and calculations of the length of the outer wall of the basal turn could be made. Measurements based on CT images have been shown to be in accordance with measurements based on histological preparations. $^{30}$

We have found that the mean cochlear length was $8.75 \mathrm{~mm}$ $(\mathrm{SD}=0.31 \mathrm{~mm})$, the mean cochlear width was $6.53 \mathrm{~mm}$ ( $\mathrm{SD}=0.35 \mathrm{~mm}$ ), and the mean cochlear height was $3.26 \mathrm{~mm}$ ( $\mathrm{SD}=0.24 \mathrm{~mm})$. A previous study by Escude et $\mathrm{al}^{11}$ found that the mean cochlear length (A) was $9.23 \mathrm{~mm}(\mathrm{SD}=0.53 \mathrm{~mm})$, and that the mean cochlear width 

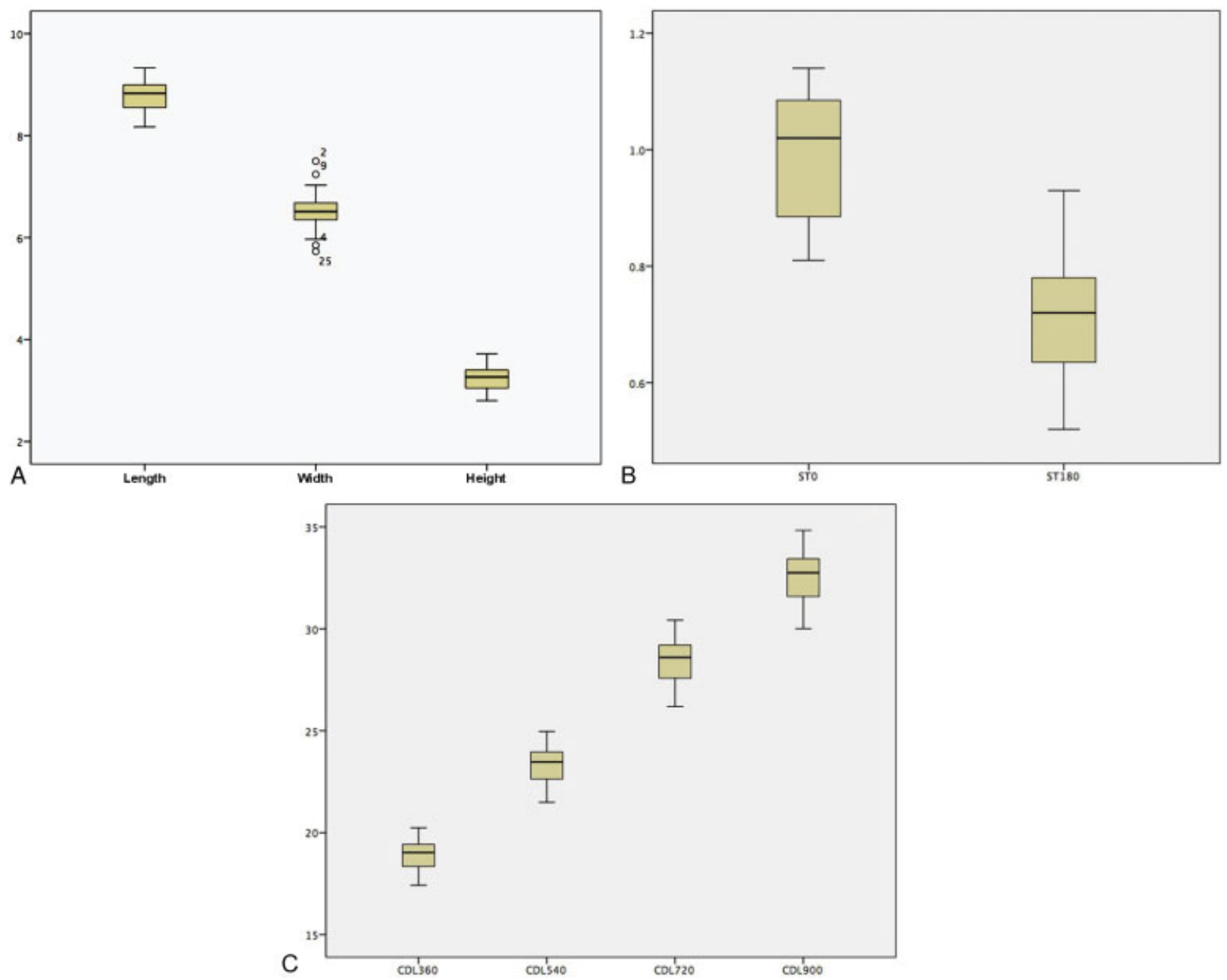

Fig. 4 (A) Box-plots of the cochlear length, width and height. (B) Scala timpani height: ST0 = scala timpani height at basal turn, ST180 = scala timpani height at half-turn. (C) Cochlear duct length at $360^{\circ}, 540^{\circ}, 720^{\circ}$ and $900^{\circ}$ of cochlear turn.

was $6.99 \mathrm{~mm}(\mathrm{SD}=0.37 \mathrm{~mm})$, which are greater than those found in the present study. A study by Pelliccia et $\mathrm{al}^{21}$ has also found that the mean cochlear length in patients with severe to profound bilateral sensorineural deafness was $9.06 \mathrm{~mm}$ (SD $=0.7 \mathrm{~mm}$ ), and that the mean cochlear width was $6.92 \mathrm{~mm}$ (range: $4.8 \mathrm{~mm}-8.5 \mathrm{~mm}$ ). Gao et $\mathrm{al}^{31}$ measured the cochlear length in Chinese people and found that the mean cochlear length among males was $9.04 \mathrm{~mm}(\mathrm{SD}=0.3 \mathrm{~mm})$, and

Table 2 Scala timpani height at basal turn $\left(0^{\circ}\right)$ and half-turn of the cochlea $\left(180^{\circ}\right)$

\begin{tabular}{|l|l|l|}
\hline & $\begin{array}{l}\text { Scala timpani } \\
\text { height } / 0^{\circ}(\mathrm{mm})\end{array}$ & $\begin{array}{l}\text { Scala timpani } \\
\text { height } / \mathbf{1 8 0}^{\circ} \\
(\mathrm{mm})\end{array}$ \\
\hline Mean & 1.00 & 0.71 \\
\hline Median & 1.02 & 0.72 \\
\hline Standard deviation & 0.10 & 0.10 \\
\hline Minimum & 0.81 & 0.52 \\
\hline Maximum & 1.14 & 0.93 \\
\hline
\end{tabular}

$8.80 \mathrm{~mm}$ (SD $=0.4 \mathrm{~mm})$ among females. The cochlear width in men was $6.7 \mathrm{~mm}(\mathrm{SD}=0.34 \mathrm{~mm})$, and $6.38 \mathrm{~mm}$ $(\mathrm{SD}=0.29 \mathrm{~mm})$ in women, which are similar to the results of the present study. Grover et $\mathrm{al}^{32}{ }^{32}$ who conducted a study with children $<6$ years of age in Jaipur, India, found that the mean cochlear length (A) was $8.12 \mathrm{~mm}$ (range: $7.7 \mathrm{~mm}-9.2 \mathrm{~mm}$ ), which is lower than the results of the present study. Both studies revealed that the cochlear length was smaller in the Asian population. Avci et $\mathrm{al}^{8}$, in Hannover, Germany, found an average cochlear length of $9.2 \mathrm{~mm}$, average cochlea width of $7.0 \mathrm{~mm}$ and average cochlear height of $4.4 \mathrm{~mm}$ in 16 freshfrozen human temporal bones without any evidence of malformation, which were then scanned using micro-CT and measured by reconstructing the micro-CT. The values found by Avci et al are greater than the results of the present study. Similarly, a research by Shin et $\mathrm{al}^{14}$ in South Korea obtained a mean cochlear height of $3.8 \mathrm{~mm}(\mathrm{SD}=0.2 \mathrm{~mm}$ ) on a micro-CT image of 39 temporal bones of corpses. A study by Hassan et $\mathrm{al}^{33}$ described the measurements of cochlear anatomy in Sudanese people, and found that the average left cochlear height was $3.6 \mathrm{~mm}(\mathrm{SD}=0.4 \mathrm{~mm})$, and that the average right cochlear height was $3.5 \mathrm{~mm}(\mathrm{SD}=0.4 \mathrm{~mm})$. 
Table 3 Cochlear duct length at 1 turn of the cochlea $\left(360^{\circ}\right), 1.5$ turns of the cochlea $\left(540^{\circ}\right), 2$ turns of the cochlea $\left(720^{\circ}\right)$, and 2.5 turns of the cochlea $\left(900^{\circ}\right)$

\begin{tabular}{|c|c|c|c|c|}
\hline & $\begin{array}{l}\text { Cochlear duct length } \\
360^{\circ}(\mathrm{mm})\end{array}$ & $\begin{array}{l}\text { Cochlear duct length } \\
540^{\circ}(\mathrm{mm})\end{array}$ & $\begin{array}{l}\text { Cochlear duct length } \\
720^{\circ}(\mathrm{mm})\end{array}$ & $\begin{array}{l}\text { Cochlear duct length } \\
900^{\circ}(\mathrm{mm})\end{array}$ \\
\hline Mean & 18.85 & 23.25 & 28.33 & 32.45 \\
\hline Median & 19.02 & 23.47 & 28.59 & 32.75 \\
\hline Standard deviation & 0.76 & 0.94 & 1.15 & 1.31 \\
\hline Minimum & 17.42 & 21.49 & 26.19 & 30.01 \\
\hline Maximum & 20.24 & 24.97 & 30.42 & 34.83 \\
\hline
\end{tabular}

Notes: $360^{\circ}=1$ turn of the cochlea; $540^{\circ}=1.5$ turns of the cochlea; $720^{\circ}=2$ turns of the cochlea; $900^{\circ}=2.5$ turns turn of the cochlea.

Several radiological studies have analyzed the correlation of CDL with the diameter of the basal cochlea, termed the " $\mathrm{A}$ " value, the length of the scala media measured from the middle of the round window to the opposite point in the basal turn through the mid-modiolar axis. ${ }^{11,26}$ Johnston et $\mathrm{al}^{26}$ determined that the CDLs (from the measurement of the "A" value) can help estimate the full insertion after the cochlear implantation, while a previous study by Escudé et $\mathrm{al}^{11}$ established a relationship between the CDL and the diameter of the basal cochlea; the study involved radiologists with extensive experience to perform image reconstructions and measurements.

The marker for the round window niche, as described by Erixon et $\mathrm{al}^{6}$ and Biedron et $\mathrm{al}^{10}{ }^{10}$ is used to measure the dimensions of the cochlea. The midpoint of the round window niche is used as the starting point of the cochlea, and the cochlear length is the line drawn from the center point of the round window niche to the opposite point through the central axis of the cochlea (mid-modiolar axis). ${ }^{11,14,34}$

Approximately $25 \%$ of the patients with congenital sensorineural hearing loss or mixed hearing loss showed malformations of the bony inner ear, which was indicated by temporal CT images, with significantly smaller cochlear height when compared to patients with normal hearing. ${ }^{35,36}$ The cochlear height plays a role in diagnosing sensorineural hearing loss in patients with hypoplasia or hyperplasia. ${ }^{33,35}$

Tarabishi et al, ${ }^{36}$ who conducted a study in Egypt, revealed that the cochlear height was an important measurement in determining subclassification and diagnosing hypoplasia and small cochleae (dwarf cochleae). The authors defined dwarf cochleae in Egyptians as morphologically normal cochleae with less than 2.5 turns, patent ducts, and a significantly reduced cochlear height detected through HRCT, which required a special modification in the surgery regarding the length of the electrode and the location of the cochleostomy during the cochlear implantation.

Manufacturers of CIs have proposed electrode arrays with a softer mechanical profile and a smaller diameter to minimize insertion trauma and ensure the proper placement of the electrodes. To determine this optimal length and the diameter of the electrode arrays, it is important to evaluate the cochlear volume by measuring the diameter of the ST in order to determine the maximum possible diameter of the electrode arrays along the cochlea. ${ }^{24}$
In the present study, the mean value of the ST height in the basal cochlea was $1.00 \mathrm{~mm}(\mathrm{SD}=0.10 \mathrm{~mm})$, and the mean value of the ST height in the half-turn of the cochlea was $0.71 \mathrm{~mm}$ ( $\mathrm{SD}=0.10 \mathrm{~mm}$ ). This value is lower than the results of previous studies by Wysocki, ${ }^{9}$ who found that the height of the ST in the basal cochlea was $1.3 \mathrm{~mm}$, and that near the apex, the height of the ST decreased by $0.25 \mathrm{~mm}$. Similarly, Biedron et $\mathrm{al}^{10}$ obtained a mean value of the ST height in the basal cochlea of $1.22 \mathrm{~mm}$ (range: 0.96$1.48 \mathrm{~mm}$ ), and of $1.08 \mathrm{~mm}$ in the half-turn of the cochlea (range: $0.87-1.28 \mathrm{~mm}$ ) on histological examinations of 28 human cochlear specimens without any evidence of labyrinth malformations. Similarly, Braun et al, ${ }^{37}$ measured the height of the ST in the temporal bone of a cadaver of a 54year-old female with absence of hearing loss, malformation or bacterial and viral contamination, and afterwards performed a micro-CT reconstruction. The measurements obtained of the ST height in the basal cochlea were $1.39 \mathrm{~mm}$, and $1.15 \mathrm{~mm}$ in the half turn of the cochlea, which were higher than the results of the present study.

The CDL is defined as the length of the scala media measured from the middle of the round window to the helicotrema. Measuring the CDL is very important in the $\mathrm{CI}$ preoperative stage. With the availability of variable length electrodes, patient-customized electrodes and reports of incomplete insertions of the longer electrodes, measuring the $\mathrm{CDL}$ before performing a $\mathrm{CI}$ is essential in order to select the appropriate electrode length. ${ }^{25,34,38}$ Alexiades et $\mathrm{al}^{34}$ reported that a single linear measurement of a CT image is believed to predict the effective total CDL. Johnston et $\mathrm{al}^{26}$ stated that the CDL (determined by the calculation of the value of $A$, the length of the cochlear basal turn) can help to estimate full insertion after CIs.

In the present study, the mean total CDL (2.5 turns) was $32.45 \mathrm{~mm}$ ( $\mathrm{SD}=1.31 \mathrm{~mm}$; range: $30.01-34.83 \mathrm{~mm}$ ). In a study using a 3D and a histopathological reconstruction, both methods obtained the mean value of the CDL from the midpoint of the round window to the helicotrema ranging

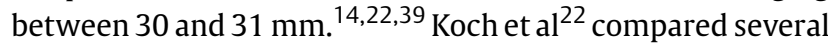
methods of measuring the CDL. Using the average direct method, the mean value of the CDL was $33.79 \mathrm{~mm}$. The indirect method resulted in a mean value of $31.31 \mathrm{~mm}$, while the $3 \mathrm{D}$ reconstruction method resulted in an average CDL of $35.04 \mathrm{~mm}$. 
There is a significant variability in the CDL in humans. ${ }^{8,39}$ This variability has clinical applications for cochlear implantation because the depth of the electrode insertion may be associated with insertion trauma and postoperative hearing function impairment. In addition, given that variations in length and electrodes tailored to the patients are available, some researchers are seriously concerned with the measurement of the CDL before the cochlear implantation in order to help determine the correct length of the electrode. ${ }^{38}$

Deep insertion of an electrode into the cochlear apex provides the maximal range of frequency stimuli, can increase the word recognition score and improve the detection of pitch at low frequencies, a more natural speech perception, ${ }^{40,41}$ and the identification of intonation. ${ }^{42} \mathrm{How}-$ ever, when placing electrodes closer to the apex, physicians should reconsider the risk of cochlear damage if using long electrodes with deep insertion. Given the significant variation in normal cochlear dimensions and with the aim of reducing trauma during the insertion, the electrode selection should be tailored for each individual. ${ }^{43}$

In the present research, we found that the minimum total $\mathrm{CDL}$ was $30.01 \mathrm{~mm}$, and the maximum total $\mathrm{CDL}$ was $34.83 \mathrm{~mm}$. This means that a CDL of $30.01 \mathrm{~mm}$ is not appropriate for the implantation of an electrode with a length of $31.5 \mathrm{~mm}$, because the electrode will be kinked at the apex, so it can damage the apical structures. Similarly, for a CDL of $34.83 \mathrm{~mm}$, when an electrode with a length of $24 \mathrm{~mm}$ is implanted, it will not cover the apex cochlea. This will cause a loss of stimulus from low frequencies, which plays a role in low pitch and intonation identification. Therefore, the preoperative measurement of the CDL becomes the guideline for the surgeon to choose the proper electrodes, with the aim of obtaining good hearing and auditory perceptions after the cochlear implantation.

\section{Conclusion}

Cochlear size varies in each individual; therefore, the measurement of temporal HRCT data of $\mathrm{CI}$ candidates is essential for the selection of suitable implant electrodes. A shallow insertion of a cochlear electrode reduces the risk of damage to apical structures, whereas a deep insertion of the array may improve the performance of the $\mathrm{CI}$ in cases of loss of residual hearing. With a proper electrode, we aim to obtain good hearing and auditory perceptions after the cochlear implantation.

The data regarding the cochlear duct may provide information to assist the design of individualized cochlear electrode insertion. The CDL should be calculated preoperatively in every patient.

\section{References}

1 Chi DH, Sabo DL. Pediatric audiology and implantable hearing devices. In: Johnson JT, Rosen CA, eds. Bailey's Head and Neck Surgery Otolaryngology. 5th ed. Philadelphia: Lippincott Williams \& Wilkins, a Wolters Kluwer business; 2014:1507-1522

2 Vincenti V, Bacciu A, Guida M, et al. Pediatric cochlear implantation: an update. Ital J Pediatr 2014;40(01):72
3 Paludetti G, Conti G, DI Nardo W, et al. Infant hearing loss: from diagnosis to therapy Official Report of XXI Conference of Italian Society of Pediatric Otorhinolaryngology. Acta Otorhinolaryngol Ital 2012;32(06):347-370

$4 \mathrm{Xu} \mathrm{J}$, Xu SA, Cohen LT, Clark GM. Cochlear view: postoperative radiography for cochlear implantation. Am J Otol 2000;21(01):49-56

5 Dimopoulos P, Muren C. Anatomic variations of the cochlea and relations to other temporal bone structures. Acta Radiol 1990;31 (05):439-444

6 Erixon E, Högstorp H, Wadin K, Rask-Andersen H. Variational anatomy of the human cochlea: implications for cochlear implantation. Otol Neurotol 2009;30(01):14-22

7 Erixon E, Liu W, Rask-Andersen H. Anatomic studies of the human cochlea: implications for cochlear implantation. The Registry 2011;19(01):1-7

8 Avci E, Nauwelaers T, Lenarz T, Hamacher V, Kral A. Variations in microanatomy of the human cochlea. J Comp Neurol 2014;522 (14):3245-3261

9 Wysocki J. Dimensions of the human vestibular and tympanic scalae. Hear Res 1999;135(1-2):39-46

10 Biedron S, Prescher A, Ilgner J, Westhofen M. The internal dimensions of the cochlear scalae with special reference to cochlear electrode insertion trauma. Otol Neurotol 2010;31 (05):731-737

11 Escudé B, James C, Deguine O, Cochard N, Eter E, Fraysse B. The size of the cochlea and predictions of insertion depth angles for cochlear implant electrodes. Audiol Neurootol 2006; 11(01, Suppl Suppl 1):27-33

12 Hardy M. The length of the organ of Corti in man. Am J Anat 1938; 62(02):291-311

13 Rask-Andersen H, Erixon E, Kinnefors A, Löwenheim H, SchrottFischer A, Liu W. Anatomy of the human cochlea-implications for cochlear implantation. Cochlear Implants Int 2011;12(Suppl (Suppl 1):S8-S13

14 Shin KJ, Lee JY, Kim JN, et al. Quantitative analysis of the cochlea using three-dimensional reconstruction based on microcomputed tomographic images. Anat Rec (Hoboken) 2013;296(07): 1083-1088

15 Verbist BM, Ferrarini L, Briaire JJ, et al. Anatomic considerations of cochlear morphology and its implications for insertion trauma in cochlear implant surgery. Otol Neurotol 2009;30(04):471-477

16 Kawano A, Seldon HL, Clark GM. Computer-aided three-dimensional reconstruction in human cochlear maps: measurement of the lengths of organ of Corti, outer wall, inner wall, and Rosenthal's canal. Ann Otol Rhinol Laryngol 1996;105(09):701-709

17 Ketten DR, Skinner MW, Wang G, Vannier MW, Gates GA, Neely JG. In vivo measures of cochlear length and insertion depth of nucleus cochlear implant electrode arrays. Ann Otol Rhinol Laryngol Suppl 1998;175:1-16

18 Kisser U, Ertl-Wagner B, Hempel JM, et al. High-resolution computed tomography-based length assessments of the cochlea-an accuracy evaluation. Acta Otolaryngol 2014;134(10):1011-1015

19 Thong JF, Low D, Tham A, Liew C, Tan TY, Yuen HW. Cochlear duct length-one size fits all? Am J Otolaryngol 2017;38(02):218-221

20 Aschendorff A. Imaging in cochlear implant patients. GMS Curr Top Otorhinolaryngol Head Neck Surg 2011;10:Doc07

21 Pelliccia P, Venail F, Bonafé A, et al. Cochlea size variability and implications in clinical practice. Acta Otorhinolaryngol Ital 2014; 34(01):42-49

22 Koch RW, Ladak HM, Elfarnawany M, Agrawal SK. Measuring Cochlear Duct Length - a historical analysis of methods and results. J Otolaryngol Head Neck Surg 2017;46(01):19

23 Teissier N, Van Den Abbeele T, Sebag G, Elmaleh-Berges M. Computed Tomography measurements of the normal and the pathologic cochlea in children. Pediatr Radiol 2010;40(03):275-283

24 Gnansia D, Demarcy T, Vandersteen C, et al. Optimal electrode diameter in relation to volume of the cochlea. Eur Ann Otorhinolaryngol Head Neck Dis 2016; 133(01, Suppl Suppl 1):S66-S67 
25 Wimmer W, Gerber N, Dhanasingh A, et al. In-vitro microCT validation of preoperative cochlear duct length estimation. CURAC 2013;1477:143-146

26 Johnston JD, Scoffings D, Chung M, et al. Computed tomography estimation of cochlear duct length can predict full insertion in cochlear implantation. Otol Neurotol 2016;37(03):223-228

27 Baskent D, Shannon RV. Speech recognition under conditions of frequency-place compression and expansion. J Acoust Soc Am 2003;113(4 Pt 1):2064-2076

28 Skinner MW, Ketten DR, Holden LK, et al. CT-derived estimation of cochlear morphology and electrode array position in relation to word recognition in Nucleus-22 recipients. J Assoc Res Otolaryngol 2002;3(03):332-350

29 James C, Albegger K, Battmer R, et al. Preservation of residual hearing with cochlear implantation: how and why. Acta Otolaryngol 2005;125(05):481-491

30 Adunka O, Unkelbach MH, Mack MG, Radeloff A, Gstoettner W. Predicting basal cochlear length for electric-acoustic stimulation. Arch Otolaryngol Head Neck Surg 2005;131(06):488-492

31 Gao Z, Tian X, Feng G. Cochlea duct length of Chinese adults for individualized cochlear electrode design. Meeting Abstract. $84^{\text {th }}$ Annual Meeting of the German Society of Oto-Rhino-Laryngology Head and Neck Surgery. Numberg: German Medical Science GMS; 2013

32 Grover M, Mishra P, Gupta G, Jangid M. Cochlear duct length: are we giving it adequate importance? Otolaryngol Head Neck Surg 2013;149(02):219-225

33 Hassan LA, Ayad CE, Hassan HA, Abdalla EA, Mohamed ME. Normative Sudanese cochlea measurements using high resolution computerized tomography. GARJMMS 2014;3(06):117-123

34 Alexiades G, Dhanasingh A, Jolly C. Method to estimate the complete and two-turn cochlear duct length. Otol Neurotol 2015;36(05):904-907
35 Purcell D, Johnson J, Fischbein N, Lalwani AK. Establishment of normative cochlear and vestibular measurements to aid in the diagnosis of inner ear malformations. Otolaryngol Head Neck Surg 2003;128(01):78-87

36 Tarabishi MN, Sarwat AA, Rabie HM, et al. Miniature cochlea: a study of radiological measurements and its implications during the cochlear implant surgery. Egypt J Otolaryngol 2016;32(03): 170-177

37 Braun K, Böhnke F, Stark T. Three-dimensional representation of the human cochlea using micro-computed tomography data: presenting an anatomical model for further numerical calculations. Acta Otolaryngol 2012;132(06):603-613

38 Deep NL, Howard BE, Holbert SO, Hoxworth JM, Barrs DM. Measurement of cochlear length using the ' $A$ ' value for cochlea basal diameter: A feasibility study. Cochlear Implants Int 2017;18 (04):226-229

39 Lee J, Nadol JB Jr, Eddington DK. Depth of electrode insertion and postoperative performance in humans with cochlear implants: a histopathologic study. Audiol Neurootol 2010;15(05):323-331

40 Hochmair I, Arnold W, Nopp P, Jolly C, Müller J, Roland P. Deep electrode insertion in cochlear implants: apical morphology, electrodes and speech perception results. Acta Otolaryngol 2003;123(05):612-617

41 Hamzavi J, Arnoldner C. Effect of deep insertion of the cochlear implant electrode array on pitch estimation and speech perception. Acta Otolaryngol 2006;126(11):1182-1187

42 Landwehr M, Fürstenberg D, Walger M, von Wedel H, Meister H. Effects of various electrode configurations on music perception, intonation and speaker gender identification. Cochlear Implants Int 2014;15(01):27-35

43 Angeli SI, Goncalves S. Predicting depth of electrode insertion by cochlear measurements on computed tomography scans. Laryngoscope 2016;126(07):1656-1661 